\title{
Practical tree fodder experience during drought
}

\author{
Alec Olsen ${ }^{1}$ and J.F.L. Charlton ${ }^{2}$ \\ ${ }^{1}$ Valhalla, 500 Glengarry Road, RD 2, Napier \\ ${ }^{2}$ Greenfields Communications, 17 Cremorne Avenue, Palmerston North
}

\begin{abstract}
Since the early 1980s willow and poplar trees originally planted for erosion control have been cut and fed to hungry livestock during droughts, with impressive results. This involves shaping trees by cutting them to develop an operating "nest" that enables the farmer to prune regrown branches with greater safety, provided forestry training has been undertaken.
\end{abstract}

More recently, trees have been planted specifically to grow supplementary fodder and some types have performed better than others. The concept is, in our opinion, quite cost-effective and the benefits of growing these trees far outweigh any drawbacks.

\section{Introduction}

During the 1960s and 1970s the then Hawke's Bay Catchment Board (now known as the Hawke's Bay Regional Council) had employees such as soil conservator Neil Faulknor, who demonstrated how to establish suitable trees, such as willows and poplars, in order to combat the effects of excessive soil moisture. These decades experienced high rainfall levels, which provided ideal establishment conditions for such trees, so good numbers of quick-growing Matsudana willows were grown in erodible gullies, and hillsides were well planted with Italian hybrid poplars (Poole, 1983).

Experience of feeding trees to animals during drought began at Valhalla when the opportunity arose during one autumn in the early 1980s. At this time Hawke's Bay farmers were always optimistic that rain would fall within the following week, and they blindly refused to accept the tragic realities of El Nino and the change this new phenomenon had brought to our "normal" weather pattern. The farms in northern Hawke's Bay would usually be over-stocked with animals and the grass disappeared into their mouths before supplementary feed could be supplied. However, most farms in the district were garnished with deliciously verdant strips growing up the gullies, which contrasted so well with the browns of droughted pastures when drought developed.

Sheep on these farms (predominantly Perendales) would try grazing weeds such as thistles when drought became severe, and they avidly consumed any leaves falling from poplar trees, but cows became hungry and anxious as the drought lengthened. The logic of feeding trees to animals was always an inherent practice, as our predecessors had hand-harvested old weeping willows to sustain the few cattle they farmed in the pioneering days. It was therefore a logical extension to use a chainsaw to prune and fell trees, and the cattle soon learned the value of such fodder in these circumstances, and that that the sound of a chainsaw was a call to fodder.

\section{Tree pruning in the past}

The common farmer practice for such trees was to "pollard" them. They were cut at a height that precluded cattle browsing, rather than the traditional "coppicing" method that involved cutting to ground level. The basic practice was to feed the trees to cattle because they were there, and the cows were hungry.

This was a simple process in the times before the Department of Occupational Safety and Health developed protocols that rebranded entrepreneurial bravery as an illegal act. Some of the techniques that farmers used to prune their trees in those times involved using chainsaws, but avoided safe practice standards or using suitable protective clothing and such practices would now be viewed with horror. Farmers harvesting their trees for feeding purposes did experience some "close calls" and many were fortunate to survive, under these circumstances. 
The only ladders generally available for tree pruning on farms were too short, and this forced farmeroperators to reach above their heads with the chainsaw, a most unfortunate and dangerous practice. They soon found that they had very little authority over the chainsaw when it was used at arm's length.

By the time the 1989 drought developed, some degree of expertise in tree pruning had been gained at Valhalla, and the horrible desperation of being responsible for starving livestock overcame some consideration of operator safety. Keeping the animals alive and easing their suffering by taking a few risks certainly seemed worthwhile, and it would have been a brave or unwise visitor who thought it necessary to admonish the farmer at the time.

\section{Safety procedures}

We do not apologise for labouring the safety message, but because willows and poplars are such a convenient resource of food in times of drought, harvesting this energy source was certainly worthwhile. The risk in harvesting tree fodder by pruning needs to be managed as well as possible, and overcoming any serious shortcomings in both equipment and technique is mostly a matter of using the right equipment properly. We urge any farmer who is considering using tree fodder by pruning established trees, to undertake appropriate training with experts.

One of the problems in cutting willow is the behaviour of the wood when it is being cut. This timber has a tendency to "shoot" (also known by operators as "barber's chair") when the harvester is partway through the cut. This hazard can develop in a fraction of a second, and has the potential to knock the pruner off his stance, or knock the active chainsaw into the operator's body. Every cut needs to be carefully considered, and certainly anyone inexperienced in using chainsaws should contemplate this task with great care before proceeding.

The operator can create a much safer position by forming a "pruning nest" in each tree. This entails cutting a willow or poplar tree across its main trunk at around five years age, at 2.00-2.5 m above ground level, which prevents cattle eating early regrowth. The strong regrowth of multiple, quite thin branches, forms a pruning nest, a cage that supports the operator with much greater safety. When using this nest for most of the felling exercise, he has something that helps to prevent a fall from the tree.

In this situation it is also advisable to wear a forestry pruning harness, especially as this helps to prevent a fall as the last few branches are cut. In addition, some thoughtful sequencing while making the cuts can improve safety standards.

The following equipment has been adopted as standard for tree pruning for fodder at Valhalla:

- Hard hat with muffs and visor.

- Chaps for leg protection.

- Forestry boots - not just steel-toed farm boots.

- Forestry workers' compression bandage pack.

- Fire extinguisher (Remember - there is a drought occurring when trees are being pruned).

- Forestry pruning ladder of suitable height.

- Pruning harness.

- Adequate drinking water.

- Short length of rope - for lowering the chainsaw or the operator.

- Efficient top-handle chainsaw - preferably a high-speed professional model.

In retrospect, an easy way to make tree harvesting much safer would be to pollard them at "sheep height" rather than "cattle height". The chainsaw work could then be undertaken without using a ladder, and with the operator situated firmly on the ground. Another recommendation from past experience would be with stock management - keep cattle out of the paddock for up to one year following harvest while the new branches regrow. 


\section{Long-term performance}

Willows and poplars are capable of regular defoliation and regenerate to supply future supplementary fodder without any bother. Several willows have been harvested by pollarding at Valhalla since the early 1980s and are growing as vigorously today as they were 20 years ago. Furthermore, they recover enough to perform their soil conservation role and also supply some shade for stock until the next pruning.

Several willows have been recorded as having been pollarded at least six times in its life to the present, and a good number of cattle and sheep have appreciated it as forage and shade. The branch debris left around the trees after pruning can be a mild nuisance, in that some weeds can germinate in its protection.

However, if the tree is reasonably accessible, the wood can be cleaned up and used as firewood. Willow is perfectly acceptable firewood if not left too long on the ground.

Cattle can sometimes strip some of the bark of willows. If sheep are also grazing a paddock containing fodder trees, they tend to consume every single leaf that the cows miss, but any pruning debris left in rougher gully situations can sometimes trap adventurous sheep. However, it does break down fairly rapidly if left behind.

The decision to harvest poplars needs to be made reasonably early in the season, before the tree starts shedding its leaves in response to the drier conditions or before poplar rust appears. Experience at Valhalla indicates that poplars should be harvested first, and willows should be saving for later use.

Yet another option for farmers is to harvest willows in mixed-species plantings if the need is great enough. However, regrowth is clearly stifled by the lack of light in these situations, and ultimately the willow stumps can fail and die.

\section{Different willow and poplars types as fodder trees}

One option for farmers keen to use tree fodder would be to create a dedicated fodder block, and with the benefit of some hindsight, most of the problems experienced in tree pollarding can be minimised.

In 1985, Matsudana, Pussy and Booth willows, and a line of Flevo poplars, were planted in an open moist area that was accessible and had a reasonable water supply nearby. The trees were pollarded at cattle height within four-five years and used specifically for supplementary fodder during summer.

During the 1994 drought these trees were harvested at different times, and gave varying regrowth thereafter. Some winners and losers were noted, with the Matsudana willows performing reliably as always. The Pussy willow's soft and palatable bark made it an easy target for ring-barking and ultimate failure. Since then there has been ample regrowth for the next drought, and some trees have been rotationally harvested to maintain control over branch size. In considering poplars, Flevo poplar (much maligned by farmers) performs quite well as a fodder resource, because it grows a multitude of branches, but it will not grow a valuable log when managed this way. However, several other poplar types and selections can also be pruned for drought fodder.

\section{Benefits and drawbacks}

On balance, we believe that using suitable trees for supplementary fodder is a worthwhile concept. Most of the safety issues encountered can be resolved, and with a little effort and imagination, most farmers could establish very useful resources of emergency food for their animals. There is even a possibility of conserving tree fodder as silage, for use in winter when needed. The feed quality aspect, with condensed tannins and other potentially beneficial ingredients, would seem to make such conservation worthwhile.

Other potential benefits include one hidden factor - the high cost of removing mature trees that have not been subjected to regular trimming. Such trees can add a significant danger threat to farmer, livestock and buildings. In addition, these trees contribute considerable beauty to our farmlands, and this must benefit the country's tourist image and enhance its reputation.

\section{Benefits:}

- The fodder exists in these trees and is available.

- It is very palatable to sheep and cattle, and they seem to perform well on it during dry periods. 
- We believe that it is cost-effective (no hay barn is needed, nor any fancy tractor equipment).

- The process is simple - and applying the KISS principle (keep it simple) is important.

- Tree fodder regenerates rapidly, and can be harvested annually if needed.

- Livestock can be retained on the farm.

- Tree fodder can be used to maintain and even improve animal production.

- There is further opportunity to create and manage an on-farm tree fodder supply.

- It also provides good clean firewood if required.

- The trees can also provide shade, shelter and aesthetic improvement.

\section{Drawbacks:}

- There are obvious dangers for operator, and sometimes the animals.

- High degree of competency with chainsaws and forest pruning procedures is absolutely essential.

- Tree fodder also produces copious quantities of wood debris.

- Weeds can grow in the area protected by debris.

\section{Threats:}

- OSH regulations - experienced tree fodder people should compile guidelines for OSH to enforce.

- Willow sawfly can threaten trees in some regions.

\section{References}

Poole, A.L., 1983. Catchment control in New Zealand. Water and Soil Miscellaneous Publication No. 48. National Water and Soil Conservation Authority, Wellington, New Zealand. 185pp. 